\section{MYD88 in the driver's seat of B-cell lymphomagenesis: from molecular mechanisms to clinical implications}

\author{
Ruben A.L. de Groen, ${ }^{1}$ Anne M.R. Schrader, ${ }^{2}$ Marie José Kersten, ${ }^{3,4,5}$ \\ Steven T. Pals ${ }^{3,5,6}$ and Joost S.P. Vermaat ${ }^{1}$
}

${ }^{1}$ Department of Hematology, Leiden University Medical Center, Leiden; ${ }^{2}$ Department of Pathology, Leiden University Medical Center, Leiden; ${ }^{3}$ Department of Hematology, Amsterdam University Medical Center, University of Amsterdam, Amsterdam; ${ }^{4}$ Lymphoma and Myeloma Center Amsterdam-LYMMCARE, Amsterdam; ${ }^{5}$ Cancer Center Amsterdam, Amsterdam and ${ }^{6}$ Department of Pathology, Amsterdam University Medical Center, Amsterdam, the Netherlands

\section{ABSTRACT}

M ore than 50 subtypes of B-cell non-Hodgkin lymphoma (B-NHL) are recognized in the most recent World Health Organization classification of 2016. The current treatment paradigm, however, is largely based on 'one-size-fits-all' immune-chemotherapy. Unfortunately, this therapeutic strategy is inadequate for a significant number of patients. As such, there is an indisputable need for novel, preferably targeted, therapies based on a biologically driven classification and risk stratification. Sequencing studies identified mutations in the MYD 88 gene as an important oncogenic driver in B-cell lymphomas. MYD 88 mutations constitutively activate NF- $\mathrm{KB}$ and its associated signaling pathways, thereby promoting $\mathrm{B}$-cell proliferation and survival. High frequencies of the hotspot MYD88(L265P) mutation are observed in extranodal diffuse large B-cell lymphoma and Waldenström macroglobulinemia, thereby demonstrating this mutation's potential as a disease marker. In addition, the presence of mutant MYD88 predicts survival outcome in B-NHL subtypes and it provides a therapeutic target. Early clinical trials targeting MYD 88 have shown encouraging results in relapsed/refractory B-NHL. Patients with these disorders can benefit from analysis for the MYD 88 hotspot mutation in liquid biopsies, as a minimally invasive method to demonstrate treatment response or resistance. Given these clear clinical implications and the crucial role of MYD88 in lymphomagenesis, we expect that analysis of this gene will increasingly be used in routine clinical practice, not only as a diagnostic classifier, but also as a prognostic and therapeutic biomarker directing precision medicine. This review focuses on the pivotal mechanistic role of mutated MYD88 and its clinical implications in B-NHL.

\section{Introduction}

With the introduction of high-throughput, next-generation sequencing, many studies have aimed to explain the diverse biology, clinical course, prognosis, and therapeutic response of B-cell non-Hodgkin lymphoma (B-NHL). This has increased our knowledge of lymphomagenesis by identifying many novel somatic alterations that affect signaling pathways involved in several B-NHL subtypes. In this rapidly evolving molecular landscape, it is important to translate newly obtained genetic knowledge directly into clinical benefit for patients. ${ }^{1}$

Ngo et al. were the first to identify an oncogenic, non-synonymous, gain-offunction mutation in myeloid differentiation primary response 88 (MYD88), leading to an amino-acid change of leucine to proline at position 265 (NM_002468.5, also referred to as position 273 in NM_001172567) of MYD88 [MYD88(L265P)]. ${ }^{2}$ Other recurrent mutations in MYD88 were likewise identified; however, the impact of these mutations has been difficult to establish due to their low prevalence. ${ }^{3}$ This review, therefore, focuses on the present understanding of the role of
Ferrata Storti Foundation
Haematologica 2019
Volume 104(12):2337-2348

\section{Correspondence:}

JOOST S.P. VERMAAT

j.s.p.vermaat@lumc.nl

Received: May 17, 2019.

Accepted: September 19, 2019.

Pre-published: November 7, 2019.

doi:10.3324/haematol.2019.227272

Check the online version for the most updated information on this article, online supplements, and information on authorship \& disclosures: www.haematologica.org/content/104/12/2337

(C)2019 Ferrata Storti Foundation

Material published in Haematologica is covered by copyright. All rights are reserved to the Ferrata Storti Foundation. Use of published material is allowed under the following terms and conditions:

https://creativecommons.org/licenses/by-nc/4.0/legalcode. Copies of published material are allowed for personal or internal use. Sharing published material for non-commercial purposes is subject to the following conditions:

https://creativecommons.org/licenses/by-nc/4.0/legalcode, sect. 3. Reproducing and sharing published material for commercial purposes is not allowed without permission in writing from the publisher. 
MYD88(L265P) in NF-кB (nuclear factor kappa-lightchain-enhancer of activated $B$ cells) activation and its association with the $\mathrm{B}$-cell receptor (BCR) cascade. In addition, we address the clinical importance of MYD88(L265P), including its prevalence across B-NHL subtypes, its predictive significance in patients' outcome, and its potential as a therapeutic target.

\section{Oncogenic mechanisms of MYD88(L265P)}

\section{Canonical NF-KB signaling}

In normal physiology, MYD88 acts as a signaling adaptor in the canonical NF- $\mathrm{KB}$ pathway (Figure 1). This pathway is activated upon recognition of pathogen-associated molecular patterns (PAMP) by receptors containing a toll/interleukin-1 receptor (TIR) domain, such as toll-like receptors (TLR) and the interleukin receptors 1 (IL-1R) and 18 (IL-18R). After ligand binding, the TIR domain of these receptors interacts with the TIR domain of MYD $88^{4}$ and this process initiates the formation of the so-called 'myddosome complex'. For this complex, activated MYD88 recruits IL-1R associated kinase 4 (IRAK4), a serine-threonine kinase, and together they phosphorylate IRAK1 or IRAK2. Phosphorylated IRAK1 and IRAK2 interact with tumor necrosis factor receptor-associated factor 6 (TRAF6), resulting in activation of transforming growth factor beta-activated kinase 1 (TAK1). ${ }^{5}$ Activated TAK1 continues signaling through the mitogen-activated protein kinase (MAPK) signaling cascade and cooperates with TAK1-binding protein (TAB) to activate the inhibitor of the NF- $\kappa B$ kinase (IKK) complex.

The IKK complex consists of the kinase subunits IKK $\alpha$ and $I K K \beta$ and the regulatory subunit NF- $\kappa B$ essential modulator. After activation, this complex phosphorylates the inhibitor of NF- $\kappa \mathrm{B}$ (I $\kappa \mathrm{B}$ ) proteins that are bound to $\mathrm{NF}-\kappa \mathrm{B}$, which prevent migration of NF- $\kappa \mathrm{B}$ to the nucleus. Phosphorylation of these I $\kappa \mathrm{B}$ proteins results in ubiquitylation and proteasomal degradation of $\mathrm{I} \kappa \mathrm{B}$ and release of the NF- $\kappa B$ subunits. Subsequently, the NF- $\kappa B$ subunits, including RELA (p65)-p50 in the classical pathway and RELB-p52 in the alternative pathway, migrate to the nucleus where they bind to specific DNA-binding sites and induce increased expression of genes involved in Bcell proliferation and survival. In addition, expression of these genes is increased through interactions between the NF- $\kappa \mathrm{B}$ subunits and other transcription factors, such as E1A binding protein P300 (EP300) and CREB binding protein (CREBBP). ${ }^{6}$

In the case of MYD88(L265P), the TIR domain of MYD88, in which L265P resides, is more highly activated compared with wildtype MYD88 and this increases downstream signaling and formation of the myddosome complex. ${ }^{2}$ Henceforth, MYD88(L265P) preferentially and

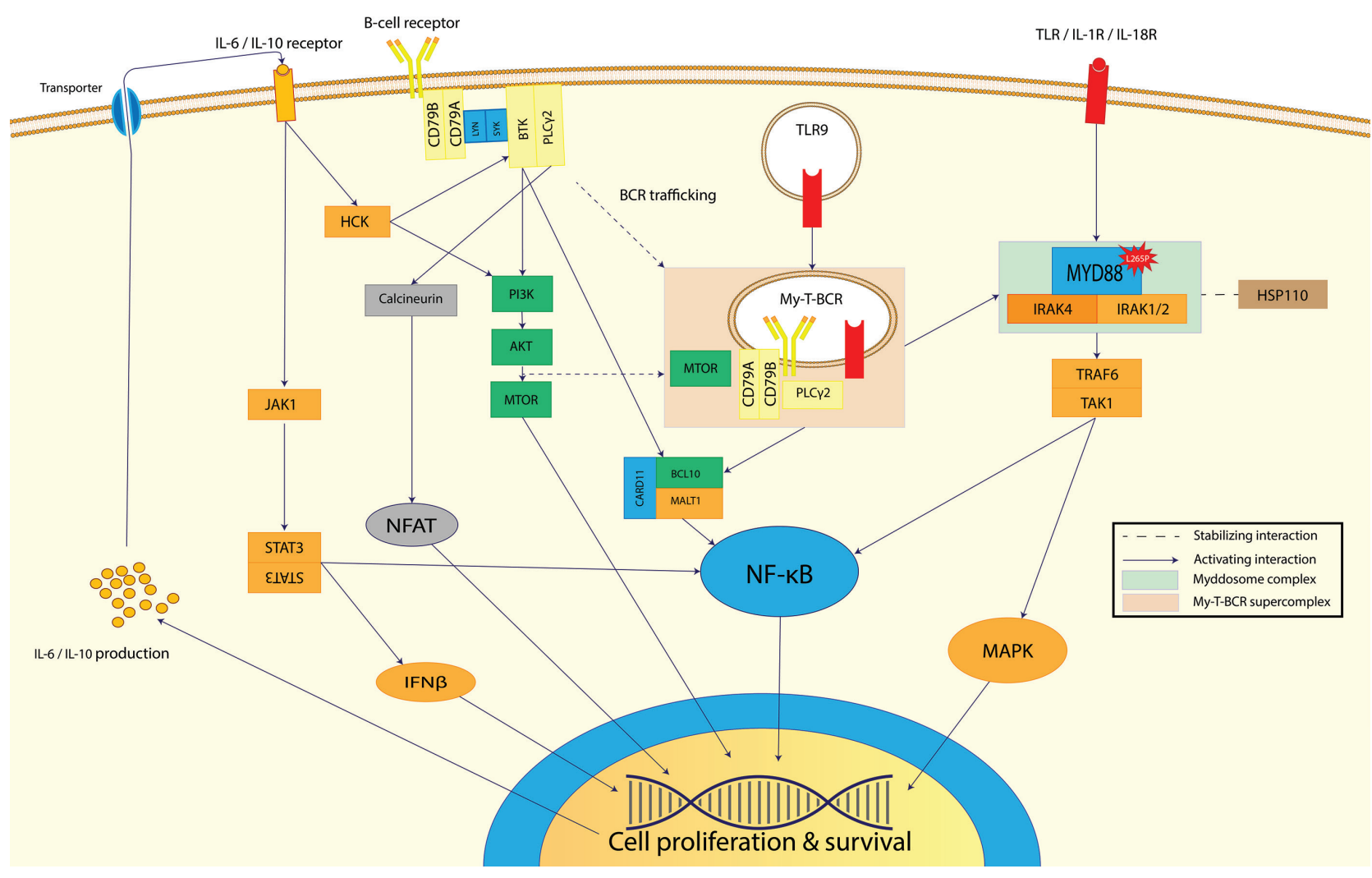

Figure 1. The role of MYD88 signaling in normal physiology and lymphomagenesis. Recognition of pathogens by TLR, IL1R, and IL-18R induces an immune response through activation of MYD88 and generates the myddosome complex with IRAK4 and IRAK1 or IRAK2, which is stabilized by HSP110. IRAK1 and IRAK2 activate the MAPK and NF-KB pathways through TRAF6 and TAK1, causing proliferation and survival of B cells. MYD88(L265P) allows for increased formation of the myddosome complex, preferentially with IRAK1, and constitutively activates the NF-KB pathway. In addition, the formation of the My-T-BCR supercomplex leads to increased activation of mTOR and the CBM complex, promoting lymphomagenesis. Lastly, constitutively active NF-KB increases autocrine signaling of IL-6 and IL-10, which further promote B-cell proliferation and survival via the alternative JAK/STAT signaling cascade. 
constitutively recruits IRAK1 for the myddosome and, together with IRAK4, was found to be essential for survival of activated $\mathrm{B}$-cell $(\mathrm{ABC})$ diffuse large B-cell lymphoma (DLBCL) cell lines with MYD88(L265P). ${ }^{2,7,8}$ In addition, IRAK1 was shown to be co-immunoprecipitated with MYD88 in chronic lymphocytic leukemia (CLL) cells with MYD88(L265P) and stimulation of IL-1R and TLR induced a 5 -fold to 150 -fold increase of cytokine secretion compared to that of CLL cells with wildtype MYD88. ' However, Ansell et al. ${ }^{7}$ identified that in Waldenström macroglobulinemia (WM) cell lines, the myddosome complex consisted of IRAK4, TRAF6, and MYD88, but not IRAK1. The authors hypothesized that this difference in complex formation was instigated by the heterozygous nature of MYD88(L265P) in WM and the homozygous nature in DLBCL, which was strengthened by the finding that downstream signaling of TAK1 phosphorylation was highest in the DLBCL cell line with homozygous MYD88(L265P). ${ }^{7}$ Furthermore, the stabilizing effect of heat shock protein 110 (HSP110) on the myddosome complex, due to interference with the proteasomal degradation of MYD88, is stronger in ABC-DLBCL cell lines with MYD88(L265P) than in those with wildtype MYD $88 .^{10}$ As MYD88(L265P) constitutively activates the NF-kB pathway, it is regarded as an important oncogenic driver in B-NHL. ${ }^{2,7-12}$

\section{B-cell receptor signaling}

In addition to the canonical NF- $\mathrm{B}$ pathway, the BCR pathway plays an important role in B-cell survival and proliferation and oncogenesis of B-NHL with MYD88 mutations (Figure 1). In normal physiology, stimulation of the BCR activates NF- $\kappa \mathrm{B}$, as well as the phosphoinositide 3-kinase (PIBK)/AKT/mammalian target of rapamycin (mTOR), and nuclear factor of activated $\mathrm{T}$ cells (NFAT) pathways. After antigen recognition by the BCR, Lck/Yes-related novel protein tyrosine kinase (LYN) is released from its inactive state through dephosphorylation of the C-terminal regulatory tyrosine by cluster of differentiation 45 (CD45) or an exogenous ligand for the Src-homology 2 (SH2) and SH3 domains of LYN, such as CD19. Activated LYN consecutively phosphorylates the immunoreceptor tyrosine-based activation motif (ITAM) domains of the coupled CD79A and CD79B heterodimers. These double-phosphorylated ITAM domains provide a docking site for the $\mathrm{SH} 2$ domains of spleen tyrosine kinase (SYK), which is activated by autophosphorylation or through transphosphorylation by LYN. LYN and SYK then activate Bruton tyrosine kinase (BTK) by phosphorylation, which is recruited to the membrane through interaction between the pleckstrin homology (PH) domain of BTK and phosphatidylinositol-3, 4, 5triphosphate (PIP3) of the PI3K pathway or through interaction between the $\mathrm{SH} 2$ domain of BTK with the B-cell linker protein (BLNK) adapter molecule that also recruits phospholipase C $\gamma 2$ (PLC $\gamma 2$ ) to the membrane. ${ }^{13}$ BTK activates PLC $\gamma 2$, initiating activation of the NF- $\kappa B$ pathway through formation of CBM complex, consisting of caspase recruitment domain family member 11 (CARD11), BCL10, and mucosa-associated lymphoid tissue lymphoma translocation protein 1 (MALT1). In addition, BTK activates the MAPK and PI3K pathways ${ }^{14}$ and PLC $\gamma 2$ triggers the NFAT pathway through calcineurin. The CBM complex subsequently attracts TRAF6, TAK1, and TAB, and promotes the degradation of $\mathrm{I} \mathrm{B}$, which leads to the release of NF- $\kappa \mathrm{B}$ subunits. ${ }^{4,5,14,15}$

BTK is an integral protein in the BCR signaling cascade and has been found to be preferentially complexed to MYD88 in WM cells with MYD88(L265P) and not in MYD88 wildtype cells. Inhibition of BTK resulted in a decrease of the formation of this MYD88-BTK complex, but lacked effect on IRAK4/IRAK1 activity and vice versa, indicating a potential necessity of dual inhibition of IRAK and BTK for WM with MYD88(L265P). ${ }^{16-18}$ MYD88 is frequently mutated in patients who also harbor a mutation in the 196 tyrosine residue in the ITAM domain of CD79B (NM_000626) and these patients seem to benefit most from BTK-inhibition treatment. ${ }^{19}$ The exact consequence of these double mutations in B-NHL is unclear, but Phelan et al. ${ }^{8}$ recently provided new insight into the mechanism of combined MYD88 and BCR-pathway activation as they identified a MYD88-TLR9-BCR (My-T$\mathrm{BCR}$ ) supercomplex. This supercomplex is generated by constitutive trafficking of the BCR towards endolysosomes that contain TLR9 and interacts with mTOR and the CBM complex, thereby promoting lymphomagenesis by activation of the $\mathrm{mTOR}$ and NF- $\mathrm{KB}$ pathways. Its presence was demonstrated in cell lines and biopsies of ABCDLBCL, primary DLBCL of the central nervous system, and lymphoplasmacytic lymphoma and correlated with responsiveness to BTK inhibition. On the other hand, the supercomplex was not identified in CLL or mantle cell lymphoma, suggesting a different mechanism of BCR signaling in these entities. Therefore, the My-T-BCR supercomplex could potentially be used as a biomarker for predicting the efficacy of BTK inhibitors, as a classifier of BNHL subtypes, or as a novel therapeutic target via inhibition of TLR9.

\section{Autocrine signaling}

As described, increased formation of the myddosome complex with IRAK1, as well as activation of the BCR pathway, caused by interactions of BTK with MYD88(L265P), CD79B mutations, and the My-T-BCR supercomplex, result in constitutive activation of the NF$\kappa \mathrm{B}$ pathway. NF- $\kappa \mathrm{B}$ not only activates the transcription of genes involved in cell survival and proliferation, but also results in autocrine signaling with IL- 6 and IL-10. One consequence of this autocrine signaling loop is the phosphorylation of Janus kinase 1 (JAK1) and, subsequently, signal transducer and activator of transcription 3 (STAT3) with the assembly of a STAT3/STAT3 complex. This complex increases transcription of genes involved in several signaling cascades, including the PI3K/AKT/mTOR, E2F/G2M cell-cycle checkpoint, JAK/STAT, and NF-кB pathways. In addition, STAT3 activity represses the proapoptotic type I interferon (IFN) signaling pathway by downregulating IFN-regulatory factor 7 (IRF7), IRF9, STAT1, and STAT2 expression. . $^{2,320}$

Another consequence of IL- 6 signaling is the aberrant expression of hematopoietic cell kinase (HCK), as identified in primary WM cells and B-NHL cell lines. ${ }^{21}$ Increased levels of HCK promote lymphomagenesis, as HCK knockdown in B-NHL cell lines reduces survival and lowers the activity of the BCR, PIBK/AKT, and MAPK/ERK (extracellular signal-regulated kinases) pathways. Furthermore, BTK- and HCK-inhibition treatment of ABC-DLBCL and WM cells with MYD88(L265P) decreased HCK expression, whereas mutant HCK(T333M) (NM_002110.4) attenuated this effect. These findings suggest that $\mathrm{HCK}$ is 
Table 1. (A, B) Overview of reported frequencies of MYD88(L265P) in B-cell neoplasms according to the 2016 World Health Organization classification of lymphoid neoplasms ${ }^{110}(A)$ and other mature B-cell neoplasms with specific disease locations (B).

$1 \mathrm{~A}$

\begin{tabular}{|c|c|c|c|c|c|c|}
\hline Mature B-cell neoplasms & $\begin{array}{l}\text { MYD88(L265P) } \\
\text { prevalence }\end{array}$ & $\begin{array}{l}\text { MYD88(L265P) } \\
\text { incidence }\end{array}$ & $\begin{array}{c}\text { Total } \\
\text { sequenced }\end{array}$ & Range & $\begin{array}{l}\text { Number } \\
\text { of studies }\end{array}$ & References \\
\hline $\begin{array}{l}\text { Chronic lymphocytic leukemia/small } \\
\text { lymphocytic lymphoma }\end{array}$ & $2.5 \%$ & 221 & 8773 & $0-25 \%$ & 41 & $18,22-24,28,38-53$ \\
\hline Monoclonal B-cell lymphocytosis & $0 \%$ & 0 & 75 & N.A. & 2 & 53,54 \\
\hline B-cell prolymphocytic leukemia & Unknown* & & & & & \\
\hline Splenic marginal zone lymphoma & $7.0 \%$ & 59 & 840 & $0-50 \%$ & 19 & $18,23,29,55,56$ \\
\hline Hairy cell leukemia & $1.1 \%$ & 1 & 89 & $0-8 \%$ & 5 & $22,30,57-59$ \\
\hline Splenic B-cell lymphoma/leukemia, unclassifiable & $16.7 \%$ & 1 & 6 & N.A. & 1 & 60 \\
\hline Lymphoplasmacytic lymphoma & $85.5 \%$ & 337 & 394 & $0-100 \%$ & 16 & $18,22-30$ \\
\hline Non-IgM lymphoplasmacytic lymphoma & $55.0 \%$ & 33 & 60 & $42-100 \%$ & 7 & $18,23,31,33,61$ \\
\hline Waldenström macroglobulinemia & $85.3 \%$ & 1888 & 2213 & $57-100 \%$ & 34 & $18,22,23,31-37$ \\
\hline $\begin{array}{l}\text { Monoclonal gammopathy of undetermined } \\
\text { significance, IgM }\end{array}$ & $52.7 \%$ & 301 & 571 & $0-100 \%$ & 13 & $18,22,23,62$ \\
\hline $\begin{array}{l}\text { Monoclonal gammopathy of undetermined } \\
\text { significance, IgG/A }\end{array}$ & $0 \%$ & 0 & 41 & N.A. & 3 & $18,22,23,34$ \\
\hline Plasma cell myeloma & $1.5 \%$ & 3 & 205 & $0-30 \%$ & 14 & $\begin{array}{l}18,22,23,30,43 \\
\quad 63,106,107\end{array}$ \\
\hline
\end{tabular}

\begin{tabular}{|c|c|c|c|c|c|c|}
\hline Solitary plasmacytoma of bone & Unknown* & & & & & \\
\hline Extraosseous plasmacytoma & Unknown* & & & & & \\
\hline Monoclonal immunoglobulin deposition diseases & Unknown* & & & & & \\
\hline $\begin{array}{l}\text { Extranodal marginal zone lymphoma of } \\
\text { mucosa-associated lymphoid tissue (MALT lymphoma) }\end{array}$ & $3.9 \%$ & 15 & 383 & $0-13 \%$ & 9 & $18,22,23,64,65$ \\
\hline Nodal marginal zone lymphoma & $10.3 \%$ & 16 & 156 & $0-71 \%$ & 9 & $18,22,23,66$ \\
\hline Follicular lymphoma & $1.9 \%$ & 5 & 264 & $0-50 \%$ & 10 & $18,22,23,67,68$ \\
\hline Pediatric-type follicular lymphoma & $0 \%$ & 0 & 27 & N.A. & 2 & 69,70 \\
\hline Large B-cell lymphoma with IRF4 rearrangement & Unknown* & & & & & \\
\hline Primary cutaneous follicle center lymphoma & $0 \%$ & 0 & 60 & N.A. & 3 & $71-73$ \\
\hline Mantle cell lymphoma & $6.7 \%$ & 2 & 30 & $0-50 \%$ & 6 & $30,43,74$ \\
\hline $\begin{array}{l}\text { Diffuse large B-cell lymphoma (DLBCL), NOS } \\
\text { Germinal center B-cell type } \\
\text { Activated B-cell type }\end{array}$ & $\begin{array}{c}15.6 \% \\
5.3 \% \\
22.9 \%\end{array}$ & $\begin{array}{c}853 \\
81 \\
492\end{array}$ & $\begin{array}{l}5457 \\
1520 \\
2151\end{array}$ & $\begin{array}{l}0-71 \% \\
0-57 \% \\
8-61 \%\end{array}$ & $\begin{array}{l}43 \\
21 \\
21\end{array}$ & $\begin{array}{c}3,18,22,23,67,75-84,113 \\
3,22,23,79-81,85 \\
3,22,23,79-81,85\end{array}$ \\
\hline T-cell/histiocyte-rich large B-cell lymphoma & Unknown* & & & & & \\
\hline Primary DLBCL of the central nervous system & $60.8 \%$ & 382 & 628 & $33-100 \%$ & 21 & $18,22,23,86-88,96$ \\
\hline Primary cutaneous DLBCL, leg type & $62.2 \%$ & 138 & 222 & $40-75 \%$ & 9 & $22,71,89-91$ \\
\hline $\mathrm{EBV}^{+}$DLBCL, NOS & $4.4 \%$ & 4 & 90 & $0-22 \%$ & 4 & $22,83,92$ \\
\hline $\mathrm{EBV}^{+}$mucocutaneous ulcer & $0 \%$ & 0 & 14 & N.A. & 1 & 93 \\
\hline DLBCL associated with chronic inflammation & Unknown* & & & & & \\
\hline Lymphomatoid granulomatosis & Unknown* & & & & & \\
\hline Primary mediastinal (thymic) large B-cell lymphoma & $0 \%$ & 0 & 68 & N.A. & 3 & $2,3,94$ \\
\hline Intravascular large B-cell lymphoma & $44.0 \%$ & 11 & 25 & N.A. & 1 & 95 \\
\hline $\mathrm{ALK}^{+}$Large B-cell lymphoma & Unknown* & & & & & \\
\hline Plasmablastic lymphoma & Unknown* & & & & & \\
\hline Primary effusion lymphoma & Unknown* & & & & & \\
\hline $\mathrm{HHV}^{+}$DLBCL, NOS & Unknown* & & & & & \\
\hline Burkitt lymphoma & $1.5 \%$ & 1 & 67 & $0-2 \%$ & 2 & 2,74 \\
\hline Burkitt-like lymphoma with 11q aberration & Unknown* & & & & & \\
\hline $\begin{array}{l}\text { High-grade B-cell lymphoma, with } M Y C \\
\text { and } B C L 2 \text { and/or } B C L 6 \text { rearrangements }\end{array}$ & $11.1 \%$ & 1 & 9 & N.A. & 1 & 83 \\
\hline High-grade B-cell lymphoma, NOS & Unknown* & & & & & \\
\hline $\begin{array}{l}\text { B-cell lymphoma, unclassifiable, with features } \\
\text { intermediate between DLBCL and classical } \\
\text { Hodgkin lymphoma }\end{array}$ & Unknown* & & & & & \\
\hline
\end{tabular}




\begin{tabular}{|c|c|c|c|c|c|c|}
\hline Other mature B-cell neoplasms with & $\begin{array}{l}\text { MYD88(L265P) } \\
\text { prevalence }\end{array}$ & $\begin{array}{l}\text { MYD88(L265P) } \\
\text { incidence }\end{array}$ & $\begin{array}{c}\text { Total } \\
\text { sequenced }\end{array}$ & Range & $\begin{array}{l}\text { Number } \\
\text { of studies }\end{array}$ & References \\
\hline Ocular adnexal marginal zone lymphoma & $9.0 \%$ & 23 & 255 & $36-71 \%$ & 6 & $22,23,105$ \\
\hline Primary bone DLBCL & $5.8 \%$ & 3 & 52 & $0-15 \%$ & 3 & 100-102 \\
\hline Primary breast DLBCL & $54.3 \%$ & 38 & 70 & $35-71 \%$ & 3 & 22,99 \\
\hline Primary cutaneous marginal zone lymphoma & $2.0 \%$ & 2 & 100 & $0-4 \%$ & 3 & 103,104 \\
\hline Primary DLBCL of the thyroid & $0 \%$ & 0 & 21 & N.A. & 1 & 22 \\
\hline Primary testicular lymphoma & $68.4 \%$ & 65 & 95 & $14-82 \%$ & 6 & $22,23,96,108$ \\
\hline Vitreoretinal lymphoma & $72.7 \%$ & 88 & 121 & $50-82 \%$ & 9 & $22,97,98$ \\
\hline
\end{tabular}

* No data found in a literature search of articles published from January 2011 until August 2019. Terms used: 'WHO terms' (MeSH terms) AND MYD88 I 'WHO terms' (MeSH Terms) AND Genetic. Additionally, all articles found by the 'WHO terms' (MeSH terms) were screened for lymphomas with unknown status of the MYD88 L265P mutation. DLBCL: diffuse large B-cell lymphoma; NOS; not otherwise specified; EBV: Epstein-Barr virus; ALK: anaplastic lymphoid kinase; HHV8: human herpes virus 8.

downstream of MYD88(L265P) and that HCK should be regarded as a potential therapeutic target in B-NHL with MYD88(L265P).

\section{Prevalence}

The described oncogenic mechanisms largely depend on the prevalence of MYD88(L265P) in B-NHL. Several studies, using Sanger sequencing, allele-specific polymerase chain reaction (PCR) analysis, or (targeted) nextgeneration sequencing, have demonstrated that the occurrence of MYD88(L265P) varies highly among the different subtypes of B-NHL (Table 1). ${ }^{2,3,18,22-108}$ The highest prevalence of MYD88(L265P) is found in lymphoplasmacytic lymphoma/WM, with approximately $85 \%$ of the patients being affected. ${ }^{18,22-37}$ In DLBCL, the prevalence of MYD88(L265P) is highest (range, $44 \%$ to $73 \%$ ) in extranodal DLBCL, in immune-privileged sites, ${ }^{96}$ such as primary DLBCL of the central nervous system ${ }^{18,22,23,86-88,96}$ and primary testicular lymphoma, ${ }^{22,23,96,108}$ primary cutaneous DLBCL, leg type, ${ }^{22,71,89-91}$ orbital/vitreoretinal DLBCL, ${ }^{22,97,98}$ intravascular large B-cell lymphoma, ${ }^{95}$ and primary breast DLBCL. ${ }^{22,99}$ The high prevalence of MYD88(L265P) in extranodal site-specific lymphomas, lymphoplasmacytic lymphoma, and WM may provide an indication for the origin of these lymphomas. Interestingly, B-NHL entities with a high prevalence of MYD88(L265P) are characterized by a monoclonal immunoglobulin $\mathrm{M}$. Furthermore, the high occurrence of MYD88(L265P) in extranodal DLBCL may imply that $B$ cells need to gain this mutation for survival and manifestation in extranodal sites.

In DLBCL in general, a recent meta-analysis by Lee et al., ${ }^{22}$ comprising 18 studies with a total of 2002 DLBCL patients, documented that 255 of $1236(21 \%)$ cases of ABC-DLBCL harbored MYD88(L265P), compared with 44 of $766(6 \%)$ cases of germinal center B-cell-like (GCB) DLBCL. Large sequencing studies, such as those by Reddy et al., ${ }^{80}$ Schmitz et al., ${ }^{81}$ Chapuy et al., ${ }^{77}$ and Intlekofer et al. ${ }^{79}$ have compared with 44 of $766(6 \%)$ cases of GCB DLBCL with archaic cell-of-origin classification, based on immunohistochemistry or gene expression profiling, and have shown that MYD88(L265P) and other mutations transcend these classifications and should be put into context with emerging genomic classification systems. These large sequencing studies underscore the need to evaluate the status of not only MYD88, but also other genes involved in B-cell lymphomagenesis for diagnosis and during treatment with targeted therapies, as proposed by Sujobert et al. ${ }^{109}$

Overall, these results identify MYD88(L265P) as a diagnostic classifier for specific B-NHL subtypes. This is supported by a recent study by our group that identified MYD88 mutations as an independent marker, in a cohort of 250 patients with DLBCL, in addition to the routinely used MYC and BCL2 and/or BCL6 rearrangements and Epstein-Barr virus status (according to the 2016 World Health Organization classification $\left.{ }^{110}\right) .{ }^{83}$ Furthermore, MYD88(L265P) is absent in primary mediastinal large Bcell lymphoma $2,3,94$ and primary cutaneous follicle center lymphoma, ${ }^{71-73}$ and rarely present in hairy cell leukemia $(1.1 \%), 22,30,57-59$ plasma cell myeloma $(1.5 \%),{ }^{18,22,23,43,106,107}$ Burkitt lymphoma (1.5\%), ,74 follicular lymphoma $(1.9 \%),{ }^{18,22,23,67,68}$ and CLL $(2.5 \%) .{ }^{18,22-24,28,38-52}$

\section{Prognostic impact}

In addition to its role as a diagnostic classifier, the prognostic value of MYD88(L265P) has been a topic of many studies involving B-NHL patients. Lee et al. performed a meta-analysis of three studies with accurate multivariate hazard ratios to investigate the prognostic value of MYD88(L265P) in DLBCL. ${ }^{22}$ This analysis, involving a total of 275 DLBCL patients, showed that DLBCL patients with MYD88(L265P) had a statistically significant inferior overall survival compared with DLBCL patients with wildtype MYD88. In addition, MYD88(L265P) was significantly associated with older age, high International Prognostic Index (IPI)-score risk groups, and extranodal localization. We also demonstrated this association of MYD88(L265P) with an inferior survival in our recent study in which we evaluated $M Y D 88$ status, together with CD79B, MYC, BCL2, BCL6 and Epstein-Barr virus status and clinical characteristics in 250 DLBCL patients. ${ }^{83}$ Additionally, we showed that the performance of the IPI score is improved by adding MYD88(L265P) as a poor risk factor.

The correlation of MYD 88 mutations with an inferior overall survival is also observed in several subtypes of extranodal DLBCL, such as primary cutaneous DLBCL, leg type ${ }^{111}$ and immune-privileged DLBCL. . $2,83,112$ On the other hand, in a study by Xu et al. ${ }^{84}$ MYD 88 mutations were significantly more frequent in DLBCL patients who 
were refractory to chemotherapy with R-CHOP (rituximab, cyclophosphamide, doxorubicin, vincristine and prednisone) $(28 \%)$ compared with DLBCL patients who were chemosensitive $(15 \%)$, but no statistically significant correlation with overall survival was found. The actual prognostic value of MYD88 in DLBCL requires further investigation, as other studies identified no effect of MYD88(L265P) on the survival of DLBCL patients. ${ }^{22,112-114}$
In other subtypes of B-NHL, such as CLL, splenic marginal zone lymphoma, and WM, MYD88(L265P9 is associated with a superior survival compared with wildtype MYD88. ${ }^{45,115,116}$ In WM, approximately $30-40 \%$ of patients present with concomitantly mutated MYD88 and CXCR 4, a gene involved in homing of $\mathrm{B}$ cells in the bone marrow, and these patients present with a greater disease burden and reduced progression-free and overall

Table 2. Overview of several (ongoing) clinical trials with novel therapies targeting BTK, PI3K, mTOR and XP01 in B-cell non-Hodgkin lymphomas in which MYD88(L265P) is frequent.

\begin{tabular}{|c|c|c|c|c|}
\hline Medication & Target & Overall response rate & B-NHL & $\begin{array}{l}\text { N. of patients } \\
\text { Ref. of trial registration }\end{array}$ \\
\hline Ibrutinib & BTK & $33 \%$ & Relapsed ABC & 12 (NCT01325701) \\
\hline Ibrutinib & BTK & $93 \%$ & WM & 55 (NCT01614821) \\
\hline Ibrutinib & BTK & $83 \%$ & PCNSL & $6^{120}$ \\
\hline Ibrutinib & BTK & $37 \%$ & ABC-DLBCL & 38 (NCT01325701) \\
\hline Ibrutinib & BTK & $5 \%$ & GCB-DLBCL & 20 (NCT01325701) \\
\hline Ibrutinib & BTK & $68-88 \%$ & Relapsed MCL & $\begin{array}{c}16 \text { (NCT02169180) } \\
139 \text { (NCT01646021) } \\
111 \text { (NCT01236391) }\end{array}$ \\
\hline Acalabrutinib & BTK & Ongoing & CLL & 306 (NCT02029443) \\
\hline Acalabrutinib & BTK & Ongoing & MCL & 124 (NCT02213926) \\
\hline Acalabrutinib & BTK & Ongoing & DLBCL & 39 (NCT03571308) \\
\hline Acalabrutinib & BTK & Ongoing & ABC-DLBCL & 21 (NCT02112526) \\
\hline Acalabrutinib & BTK & Ongoing & MCL & 70 (NCT02717624) \\
\hline Zanubrutinib & BTK & Ongoing & B-cell lymphoma & 44 (NCT03189524) \\
\hline Zanubrutinib & BTK & Ongoing & Relapsed MCL & 86 (NCT03206970) \\
\hline Zanubrutinib & BTK & Ongoing & Relapsed WM & 40 (NCT03332173) \\
\hline Zanubrutinib & BTK & Ongoing & Relapsed CLL & 91 (NCT03206918) \\
\hline Zanubrutinib & BTK & Ongoing & Relapsed MZL & 65 (NCT03846427) \\
\hline Zanubrutinib & BTK & Ongoing & WM & 210 (NCT03053440) \\
\hline Enzastaurin & PKC & & MCL & 61 (NCT00088205) \\
\hline Enzastaurin & PKC & & Relapsed DLBCL & 55 (NCT00042666) \\
\hline Enzastaurin & PKC & & Relapsed WM & 46 (NCT00718419) \\
\hline Buparlisib & PI3K & $11.5 \%$ & Relapsed DLBCL & 26 (NCT01693614) \\
\hline Buparlisib & PI3K & $22.7 \%$ & Relapsed MCL & 22 (NCT01693614) \\
\hline Buparlisib & PI3K & $25 \%$ & PCNSL & 4 (NCT02301364) \\
\hline Idelalisib & PI3K & $40 \%$ & Relapsed MCL & 40 (NCT01090414) \\
\hline Idelalisib & PI3K & $47 \%$ & Relapsed MZL & 15 (NCT01282424) \\
\hline Idelalisib & PI3K & $80 \%$ & Relapsed LPLWM & 10 (NCT01282424) \\
\hline Parsaclisib & PI3K & $30 \%$ & Relapsed DLBCL & 23 (NCT02018861) \\
\hline Parsaclisib & PI3K & $67 \%$ & Relapsed MCL & 14 (NCT02018861) \\
\hline Parsaclisib & PI3K & $78 \%$ & Relapsed MZL & 9 (NCT02018861) \\
\hline Everolimus & mTOR & $20-32 \%$ & Relapsed MCL & $\begin{array}{c}35 \text { (NCT00516412) } \\
19^{141}\end{array}$ \\
\hline Everolimus & mTOR & $70 \%$ & Relapsed WM & 51 (NCT00436618) \\
\hline Everolimus & mTOR & $30 \%$ & Relapsed DLBCL & $47^{141}$ \\
\hline Temsirolimus & mTOR & $32-47 \%$ & Relapsed MCL & $\begin{array}{l}47 \text { (NCT01180049) } \\
141 \text { (NCT01646021) }\end{array}$ \\
\hline IMO-8400 & TLR7/8/9 & & Relapsed DLBCL & 6 (NCT02252146) \\
\hline IMO-8400 & TLR7/8/9 & & Relapsed WM & 5 (NCT02363439) \\
\hline
\end{tabular}

B-NHL: B-cell non-Hodgkin lymphomas; BTK: Bruton tyrosine kinase; PKC: protein kinase C; PI3K: phosphoinositide 3-kinase; mTOR: mammalian target of rapamycin;TLR: tolllike receptor; ABC: activated B-cell; DLBCL: diffuse large B-cell lymphoma;WM:Waldenström macroglobulinemia; PCNSL: primary DLBCL of the central nervous system; GCB: germinal center B-cell like; MCL: mantle cell lymphoma; CLL: chronic lymphocytic leukemia; MZL; marginal zone lymphoma; LPL; lymphoplasmacytic lymphoma. 
survival. ${ }^{117,118}$ With regards to CLL, Improgo et al. ${ }^{39}$ stated that MYD88(L265P) occurs mainly in patients with mutated IGHV or chromosome $13 \mathrm{q}$ deletions and both alterations are associated with a superior survival. Furthermore, WM patients with wildtype MYD 88 had an increased risk of disease transformation, ibrutinib resistance and shorter overall survival. ${ }^{9,117,118}$

\section{Targeted therapies}

The oncogenic activity of MYD88(L265P), as well as its high frequency in several B-NHL subtypes, ensure that MYD88 and its affiliated signaling pathways are very interesting for targeted therapeutic strategies. As reviewed by Yu et al. ${ }^{18}$ and Weber et al., ${ }^{119}$ several targets are conceivable for direct or indirect inhibition, such as IRAK1 and IRAK4 in the myddosome-complex, TAK1 in downstream signaling, BTK in the BCR pathway, TLR9 in the My-T-BCR supercomplex, and components of the concurrently activated PI3K/AKT/mTOR and HCK pathways (Figure 2).

Of these targets, inhibition of BTK has been the most extensively studied, regardless of the fact that BTK is not a MYD88(L265P)-specific target and is not directly involved with the myddosome complex. The BTK inhibitor ibrutinib is approved as treatment for CLL, mantle cell lymphoma, relapsed/refractory marginal zone lymphoma, and WM by the United States Food and Drug Administration (FDA). Additionally, the FDA permitted the combined use of ibrutinib and rituximab as the first non-chemotherapeutic regimen for WM patients. In early clinical trials in patients with relapsed/refractory DLBCL and primary DLBCL of the central nervous system, ibrutinib elicited an overall response rate of $80-85 \%$ in those with MYD88(L265P) alone or in combination with mutated $C D 79 B \cdot{ }^{19,120}$ Furthermore, in a randomized phase III trial, ibrutinib plus R-CHOP improved the overall survival of DLBCL patients younger than 60 years regardless of the cell-of-origin. ${ }^{121}$ Nonetheless, ibrutinib tends to produce many off-target effects and acquisition of resistance to the drug is common. For instance, ibrutinib resistance can be caused by the C481S mutation in BTK (NM_000061), which hampers the interaction between ibrutinib and BTK, ${ }^{122}$ but also by mutations in PLC $\gamma 2,{ }^{123}$ CARD 11, ${ }^{120}$ and CXCR $4 .{ }^{124}$ Given these drawbacks of ibrutinib, next-generation BTK inhibitors, such as acalabrutinib and zanubrutinib, are being developed and used for research. Studies demonstrated that acalabrutinib achieved an overall response rate of $95 \%$ in relapsed $\mathrm{CLL}^{125}$ and $81 \%$ in relapsed mantle cell lymphoma, ${ }^{126}$ and this medicine is now approved as treatment for mantle cell lymphoma by the United States FDA. Zanubrutinib achieved an overall response rate of $90 \%$ in WM, and was also shown to be well tolerated and to overcome the ibrutinib resistance mechanism induced by CXCR4 mutations. ${ }^{127}$

In addition to studies on BTK inhibition, several phase I/II clinical trials have investigated the response of novel therapeutic targets (in)directly involved with MYD88 in patients with B-NHL. In relapsed/refractory WM, mTOR inhibition with everolimus produced an overall response rate of $50 \% .{ }^{128}$ In several subtypes of relapsed/refractory B-NHL, PI3K inhibition with parsaclisib produced overall response rates ranging between $20 \%$ and $78 \%$, with a low risk of adverse events and improved long-term out-

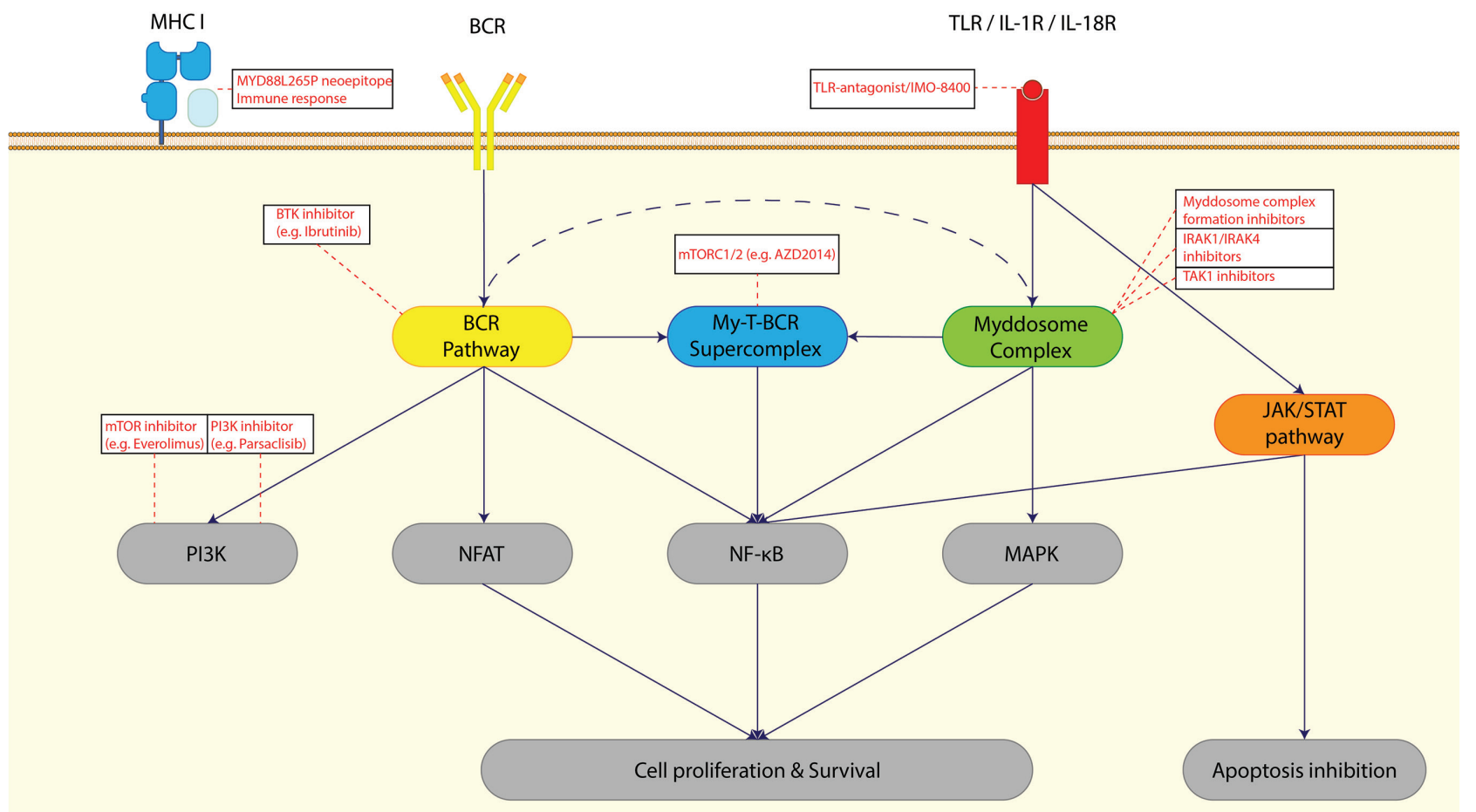

Figure 2. Signaling cascades in mutated MYD88 B-cell non-Hodgkin lymphoma can be inhibited by several targeted therapeutic strategies. A combination of several therapies might increase efficacy and reduce the risk of relapse, depending on the molecular profile of the B-cell non-Hodgkin lymphoma. 


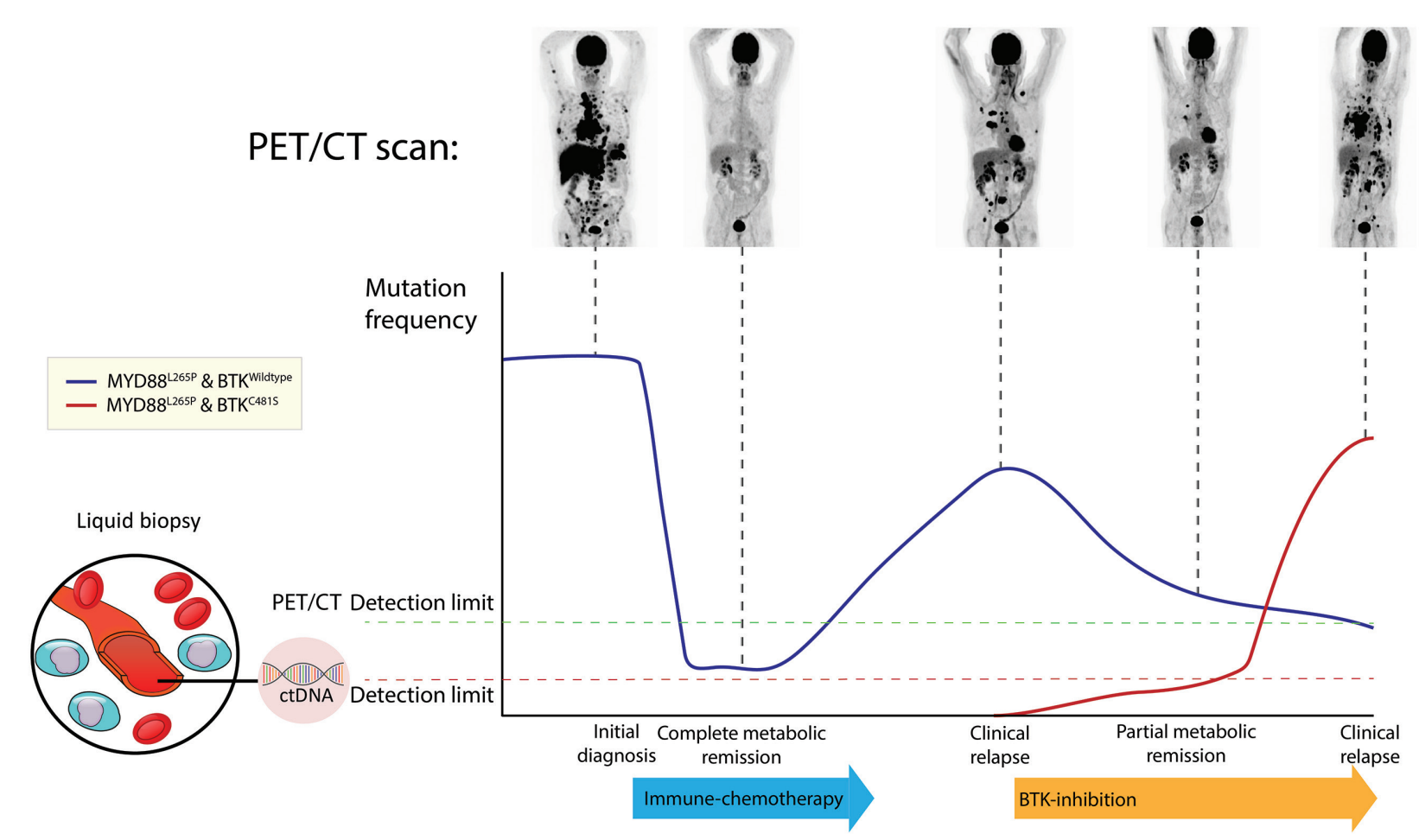

Figure 3. Schematic representation of the potential use of liquid biopsies during disease progression in B-cell non-Hodgkin lymphoma. After diagnosis, a hypothetical patient was treated with immune-chemotherapy. During therapy, the lymphoma was significantly reduced, as evidenced by a complete metabolic remission on positron emission tomography-computed tomography (PET/CT) scans and minimal residual disease by the analysis of circulating tumor DNA (ctDNA) mutation frequency. Thereafter, the residual B-cell lymphoma developed again, gradually increased, and induced a significant clinical relapse. Following comprehensive (genetic) diagnostic procedures, including histological confirmation, liquid biopsies, and PET/CT scans, the patient was treated with BTK inhibition as a second-line therapy, consequently reducing the lymphoma and leading to a partial metabolic remission. Lastly, residual lymphoma cells harboring a BTK(C481S) mutation gained resistance to the BTK inhibition therapy; these cells expanded unimpeded and resulted in another clinical relapse. In this schematic representation, the mutation frequency throughout the course of the patient's disease is plotted. The two detection limits indicate the sensitivity of PET/CT and the liquid biopsy (e.g., ctDNA with digital droplet polymerase chain reaction analysis).

comes. ${ }^{129}$ In in vitro assays, enzastaurin, a protein kinase C inhibitor, reduced proliferation and viability of DLBCL cells by regulation of the PIBK, MAPK, and JAK/STAT pathways; however, it also increased phosphorylation of BTK, suggesting the need for simultaneous treatment of enzastaurin with BTK inhibition. ${ }^{130}$ Patients with DLBCL are currently being recruited into a phase III clinical trial in which enzastaurin is combined with R-CHOP (NCT03263026).

The clinical trials mentioned above focus on therapeutic targets that are directly or indirectly involved with MYD88 activity; however these targets are not specific for MYD88(L265P) and patients are selected irrespective of the mutational status of MYD88. The lack of biomarkers in these clinical trials is a potential weakness, especially regarding the evolving field of genetics and precision medicine. Novel drugs targeting the oncogenic mechanisms of MYD88(L265P), such as inhibition of the interaction between TLR9 and MYD88 in the My-T-BCR supercomplex $^{8}$ and between MYD88 and IRAK4 in the myddosome, ${ }^{131}$ or direct inhibition of IRAK $4^{11,39}$ or TAK $1,{ }^{7}$ would be interesting for B-NHL patients with MYD88(L265P) and have shown promising results in in vitro and in vivo studies. In addition, the use of immunomodulatory oligonucleotides (IMO) such as IMO 8400, an antagonist of TLR7, TLR8, and TLR9, could be an interesting targeted treatment for MYD88(L265P) B-NHL and especially for ABC-DLBCL with the My-T-BCR supercomplex. IMO-8400 has mainly been investigated in immune-mediated inflammatory diseases and only two phase I/II clinical trials with MYD88(L265P)-positive DLBCL and WM have been performed, showing that $\mathrm{IMO}-8400$ is well tolerated in these patients (NCT02252146, NCT02363439, https://www.iderapharma.com/wp-content/uploads/2015/12/IMO-8400-WMASH-Poster.pdf). More research is required on the MYD88(L265P)-specificity of the above-mentioned targets in order to determine their role in the treatment of B-NHL patients with MYD88(L265P) and, thereby, improve personalized medicine.

An alternative therapeutic approach for these patients, as reviewed by Weber et al. ${ }^{119}$ is the induction of a T-cell mediated immune response towards tumor-specific neoepitopes that are derived from MYD88(L265P). In in vitro experiments, such neoepitopes, presented by major histocompatibility class I molecules, prompted a cytotoxic $\mathrm{CD}^{+}$T-cell response. ${ }^{132}$ These tumor-specific $\mathrm{T}$ cells can be harvested from healthy donors ${ }^{133}$ or patients with B-NHL and primed to elicit a tumor-specific cytotoxic effect or theoretically used as a model for chimeric antigen receptor (CAR) T-cell therapy. Furthermore, in vitro assays of DLBCL showed that MYD88(L265P) tumor cells develop resistance against $\mathrm{T}$-cell mediated cytotoxicity via upregulation of IL-10 and STAT3 and that inhibition of either IL-10 or STAT3 significantly attenuates this gain 
of resistance. ${ }^{134}$ To our knowledge, currently no clinical trials are underway to investigate this intriguing treatment concept.

\section{Liquid biopsy}

Until now, comprehensive genomic analysis for accurate diagnosis and classification of B-NHL has been based on DNA isolated from lymphoma tissues. For most patients, the collection of this tissue is a highly invasive procedure with the risk of severe complications. ${ }^{135}$ An alternative and less invasive method of sampling is the so-called 'liquid biopsy', using blood plasma or cerebrospinal fluid, instead of lymphoma tissue. These fluids contain circulating tumor DNA (ctDNA) that is secreted or released during apoptosis or necrosis of the tumor cells, and may harbor somatic mutations, such as MYD88(L265P). Besides being a less invasive method of sampling, ctDNA allows detection of spatial differences between lymphoma cells spread throughout the body, which is not possible with tissue biopsies.

The high frequency of MYD88(L265P) in several B-NHL subtypes make this mutation perfectly appropriate for screening by ctDNA, as already demonstrated in DLBCL, ${ }^{136}$ primary DLBCL of the central nervous system, ${ }^{137}$ and intravascular large B-cell lymphoma..$^{95}$ With the highly sensitive and specific method of digital droplet PCR (ddPCR), even low amounts of ctDNA can be detected, potentially providing information about minimal residual disease, clonal evolution over time, and spatial differences between the lymphoma cells. As demonstrated in patients with DLBCL and WM, ddPCR analysis of liquid biopsies can aid in monitoring the disease course, because of the highly sensitive identification and quantification of the variant allele frequency of MYD88(L265P). ${ }^{31,138}$

An alternative technique for ctDNA analysis is targeted next-generation sequencing. The benefit of this technique over ddPCR is the possibility of identifying multiple variants at the same time, as was shown by Bohers et al. ${ }^{139}$ and Kurtz et al. ${ }^{140}$ in liquid biopsies from 30 and 217 DLBCL patients, respectively. The mutational burden of most of their patients, with a median of 117 variants per patient, was sufficient for disease monitoring. This novel way of disease monitoring could enhance evaluation of treatment responses (Figure 3). In their studies, the tumor burden, as measured by positron emission tomographycomputed tomography scans, was significantly correlated with the variant allele frequency of ctDNA both during and after treatment. ${ }^{139,140}$ Given this recent progress in ctDNA analysis, liquid biopsies are a minimally invasive method for evaluation of the molecular profile and can be used for analysis of tumor burden, disease progression, and treatment efficacy in patients with B-NHL.

\section{Conclusions and future perspectives}

Routine diagnostics in B-NHL are moving forward from classical morphology and immunohistochemistry towards the implementation of genetic analysis. In several subtypes of B-NHL subtype, MYD88(L265P) plays a crucial role as a driver of lymphomagenesis and can be used as a diagnostic classifier, as well as a prognostic factor and predictive biomarker. B-NHL with MYD88(L265P) can be (in)directly targeted by several novel therapeutic strategies and prospective clinical trials investigating these strategies are ongoing. We expect that that these theranostic strategies will be guided by analysis of MYD88(L265P) in liquid biopsies to monitor disease progression and determine response to therapy. Altogether, given the significant clinical relevance of MYD88(L265P), we advocate evaluation of MYD88 mutational status in routine diagnostics of B-NHL.

\section{References}

1. Vermaat JS, Pals ST, Younes A, et al. Precision medicine in diffuse large B-cell lymphoma: hitting the target. Haematologica. 2015;100(8):989-993.

2. Ngo VN, Young RM, Schmitz R, et al. Oncogenically active MYD88 mutations in human lymphoma. Nature. 2011;470(7332): 115-119.

3. Dubois S, Viailly PJ, Bohers E, et al. Biological and clinical relevance of associated genomic alterations in MYD88 L265P and non-L265P-mutated diffuse large B-cell lymphoma: analysis of 361 cases. Clin Cancer Res. 2017;23(9):2232-2244.

4. Deguine J, Barton GM. MyD88: a central player in innate immune signaling. F1000Prime Rep. 2014;6:97.

5. Lin SC, Lo YC, Wu H. Helical assembly in the MyD88-IRAK4-IRAK2 complex in TLR/IL-1R signalling. Nature. 2010;465 (7300):885-890.

6. Perkins ND. The diverse and complex roles of NF-kappaB subunits in cancer. Nat Rev Cancer. 2012;12(2):121-132.

7. Ansell SM, Hodge LS, Secreto FJ, et al. Activation of TAK1 by MYD88 L265P drives malignant B-cell growth in non-Hodgkin lymphoma. Blood Cancer J. 2014;4:e183.
8. Phelan JD, Young RM, Webster DE, et al. A multiprotein supercomplex controlling oncogenic signalling in lymphoma. Nature. 2018;560(7718):387-391.

9. Puente XS, Pinyol M, Quesada V, et al. Whole-genome sequencing identifies recurrent mutations in chronic lymphocytic leukaemia. Nature. 2011:475(7354):101-105.

10. Boudesco C, Verhoeyen E, Martin L, et al. HSP110 sustains chronic NF-kappaB signaling in activated B-cell diffuse large B-cell lymphoma through MyD88 stabilization. Blood. 2018;132(5):510-520.

11. Ni HW, Shirazi F, Baladandayuthapani V, et al. Targeting myddosome signaling in Waldenstrom's macroglobulinemia with the interleukin-1 receptor-associated kinase 1/4 inhibitor R191. Clin Cancer Res. 2018;24 (24):6408-6420.

12. Rousseau S, Martel G. Gain-of-function mutations in the toll-like receptor pathway: TPL2-mediated ERK1/ERK2 MAPK activation, a path to tumorigenesis in lymphoid neoplasms? Front Cell Dev Biol. 2016;4:50.

13. Kurosaki T, Hikida M. Tyrosine kinases and their substrates in B lymphocytes. Immunol Rev. 2009;228(1):132-148

14. Xu Y, Xu L, Zhao M, et al. No receptor stands alone: IgG B-cell receptor intrinsic and extrinsic mechanisms contribute to anti- body memory. Cell Res. 2014;24(6):651-664 15. Knittel G, Liedgens P, Korovkina D, Pallasch CP, Reinhardt HC. Rewired NFkappaB signaling as a potentially actionable feature of activated B-cell-like diffuse large B-cell lymphoma. Eur J Haematol. 2016;97(6):499-510.

16. Yang G, Zhou Y, Liu X, et al. A mutation in MYD88 (L265P) supports the survival of lymphoplasmacytic cells by activation of Bruton tyrosine kinase in Waldenstrom macroglobulinemia. Blood. 2013;122(7): 1222-1232.

17. Wang JQ, Jeelall YS, Humburg P, et al Synergistic cooperation and crosstalk between MYD88(L265P) and mutations that dysregulate CD79B and surface IgM. J Exp Med. 2017;214(9):2759-2776.

18. Yu X, Li W, Deng Q, et al. MYD88 L265P mutation in lymphoid malignancies. Cancer Res. 2018;78(10):2457-2462.

19. Wilson WH, Young RM, Schmitz R, et al Targeting B cell receptor signaling with ibrutinib in diffuse large B cell lymphoma. Nat Med. 2015;21(8):922-926.

20. Lu L, Zhu F, Zhang M, et al. Gene regulation and suppression of type I interferon signaling by STAT3 in diffuse large B cell lymphoma. Proc Natl Acad Sci U S A 2018;115(3):E498-E505.

21. Yang G, Buhrlage SJ, Tan L, et al. HCK is a 
survival determinant transactivated by mutated MYD88, and a direct target of ibrutinib. Blood. 2016;127(25):3237-3252.

22. Lee JH, Jeong H, Choi JW, Oh H, Kim YS. Clinicopathologic significance of MYD88 L265P mutation in diffuse large B-cell lymphoma: a meta-analysis. Sci Rep. 2017;7 (1): 1785

23. Onaindia A, Medeiros LJ, Patel KP. Clinical utility of recently identified diagnostic, prognostic, and predictive molecular biomarkers in mature B-cell neoplasms. Mod Pathol. 2017:30(10):1338-1366

24. Baer C, Dicker F, Kern W, Haferlach T, Haferlach C. Genetic characterization of MYD88-mutated lymphoplasmacytic lymphoma in comparison with MYD88-mutated chronic lymphocytic leukemia. Leukemia. 2017;31(6):1355-1362.

25. Ballester LY, Loghavi S, Kanagal-Shamanna $\mathrm{R}$, et al. Clinical validation of a CXCR4 mutation screening assay for Waldenstrom macroglobulinemia. Clin Lymphoma Myeloma Leuk. 2016;16(7):395-403.

26. Cilla N, Vercruyssen M, Ameye L, et al. [Diagnostic approach of an IgM monoclonal gammopathy and clinical importance of gene MYD88 L265P mutation]. Rev Med Brux. 2018 May 30. [Epub ahead of print]

27. Fang H, Kapoor P, Gonsalves WI, et al. Defining lymphoplasmacytic lymphoma: does MYD88L265P define a pathologically distinct entity among patients with an IgM paraprotein and bone marrow-based lowgrade B-cell lymphomas with plasmacytic differentiation? Am J Clin Pathol. 2018:150(2):168-176.

28. Insuasti-Beltran G, Gale JM, Wilson CS, Foucar K, Czuchlewski DR. Significance of MYD88 L265P mutation status in the subclassification of low-grade B-cell lymphoma/leukemia. Arch Pathol Lab Med. 2015;139(8):1035-1041.

29. Martinez-Lopez A, Curiel-Olmo S, Mollejo M, et al. MYD88 (L265P) somatic mutation in marginal zone B-cell lymphoma. Am J Surg Pathol. 2015;39(5):644-651.

30. Ondrejka SL, Lin JJ, Warden DW, Durkin L, Cook JR, Hsi ED. MYD88 L265P somatic mutation: its usefulness in the differential diagnosis of bone marrow involvement by B-cell lymphoproliferative disorders. Am J Clin Pathol. 2013;140(3):387-394

31. Drandi D, Genuardi E, Dogliotti I, et al. Highly sensitive MYD88(L265P) mutation detection by droplet digital polymerase chain reaction in Waldenstrom macroglobulinemia. Haematologica. 2018;103(6):10291037

32. Poulain S, Roumier C, Decambron A, et al. MYD88 L265P mutation in Waldenstrom macroglobulinemia. Blood. 2013;121(22): 4504-4511

33. Varettoni M, Boveri E, Zibellini S, et al. Clinical and molecular characteristics of lymphoplasmacytic lymphoma not associated with an IgM monoclonal protein: a multicentric study of the rete ematologica lombarda (REL) network. Am J Hematol. 2019 Aug 4. [Epub ahead of print]

34. Xu L, Hunter ZR, Tsakmaklis N, et al. Clonal architecture of CXCR4 WHIM-like mutations in Waldenstrom macroglobulinaemia. Br J Haematol. 2016;172(5):735-744.

35. Xu L, Hunter ZR, Yang G, et al. Detection of MYD88 L265P in peripheral blood of patients with Waldenstrom's macroglobulinemia and IgM monoclonal gammopathy of undetermined significance. Leukemia. 2014;28(8):1698-1704.

36. Treon SP, Cao Y, Xu L, Yang G, Liu X,
Hunter ZR. Somatic mutations in MYD88 and CXCR4 are determinants of clinical presentation and overall survival in Waldenstrom macroglobulinemia. Blood. 2014;123(18):2791-2796.

37. Abeykoon JP, Paludo J, King RL, et al. MYD88 mutation status does not impact overall survival in Waldenstrom macroglobulinemia. Am J Hematol. 2018;93(2):187-194.

38. Ali YB, Foad RM, Abdel-Wahed E. Lack of associations between TLR9 and MYD88 gene polymorphisms and risk of chronic lymphocytic leukemia. Asian Pac J Cancer Prev. 2017;18(12):3245-3250.

39. Improgo MR, Tesar B, Klitgaard JL, et al. MYD88 L265P mutations identify a prognostic gene expression signature and a pathway for targeted inhibition in CLL. Br J Haematol. 2019:184(6):925-936.

40. Jiang M, Li J, Zhou J, Xing C, Xu JJ, Guo F. High-resolution melting analysis for rapid and sensitive MYD88 screening in chronic lymphocytic leukemia. Oncol Lett. 2019;18(1):814-821

41. Leeksma AC, Taylor J, Wu B, et al. Clonal diversity predicts adverse outcome in chronic lymphocytic leukemia. Leukemia. 2019:33(2):390-402

42. Maleki Y, Alahbakhshi Z, Heidari Z, et al. NOTCH1, SF3B1, MDM2 and MYD88 mutations in patients with chronic lymphocytic leukemia. Oncol Lett. 2019;17(4):4016 4023.

43. Patkar N, Subramanian PG, Deshpande P, et al. MYD88 mutant lymphoplasmacytic lymphoma/Waldenstrom macroglobulinemia has distinct clinical and pathological features as compared to its mutation negative counterpart. Leuk Lymphoma. 2015;56(2):420425.

44. Putowski M, Podgorniak M, Pirog M, et al. Prognostic impact of NOTCH1, MYD88, and SF3B1 mutations in Polish patients with chronic lymphocytic leukemia. Pol Arch Intern Med. 2017;127(4):238-244.

45. Oin SC, Xia Y, Miao Y, et al. MYD88 mutations predict unfavorable prognosis in chronic lymphocytic leukemia patients with mutated IGHV gene. Blood Cancer J. 2017;7(12):651

46. Quijada-Alamo M, Hernandez-Sanchez M, Robledo C, et al. Next-generation sequencing and FISH studies reveal the appearance of gene mutations and chromosomal abnormalities in hematopoietic progenitors in chronic lymphocytic leukemia. J Hematol Oncol. 2017;10(1):83.

47. Rigolin GM, Saccenti E, Bassi C, et al Extensive next-generation sequencing analysis in chronic lymphocytic leukemia at diagnosis: clinical and biological correlations. Hematol Oncol. 2016;9(1):88

48. Rizzo D, Chauzeix J, Trimoreau F, et al. IgM peak independently predicts treatment-free survival in chronic lymphocytic leukemia and correlates with accumulation of adverse oncogenetic events. Leukemia. 2015;29(2): 337-345.

49. Rossi D, Rasi S, Spina V, et al. Integrated mutational and cytogenetic analysis identifies new prognostic subgroups in chronic lymphocytic leukemia. Blood. 2013;121(8): 1403-1412

50. Sutton LA, Young E, Baliakas P, et al. Different spectra of recurrent gene mutations in subsets of chronic lymphocytic leukemia harboring stereotyped B-cell receptors. Haematologica. 2016;101(8):959967

51. Vollbrecht C, Mairinger FD, Koitzsch U, et al. Comprehensive analysis of disease-related genes in chronic lymphocytic leukemia by multiplex PCR-based next generation sequencing. PLoS One. 2015;10(6):e0129544.

52. Wu SJ, Lin CT, Agathangelidis A, et al. Distinct molecular genetics of chronic lymphocytic leukemia in Taiwan: clinical and pathogenetic implications. Haematologica. 2017;102(6):1085-1090

53. Puente XS, Bea S, Valdes-Mas R, et al. Noncoding recurrent mutations in chronic lymphocytic leukaemia. Nature. 2015;526 (7574):519-524.

54. Agathangelidis A, Ljungstrom V, Scarfo L, et al. Highly similar genomic landscapes in monoclonal B-cell lymphocytosis and ultrastable chronic lymphocytic leukemia with low frequency of driver mutations. Haematologica. 2018;103(5):865-873.

55. Clipson A, Wang M, de Leval L, et al. KLF2 mutation is the most frequent somatic change in splenic marginal zone lymphoma and identifies a subset with distinct genotype. Leukemia. 2015;29(5):1177-1185.

56. Traverse-Glehen A, Bachy E, Baseggio L, et al. Immunoarchitectural patterns in splenic marginal zone lymphoma: correlations with chromosomal aberrations, IGHV mutations, and survival. A study of 76 cases. Histopathology. 2013;62(6):876-893

57. Jallades L, Baseggio L, Sujobert P, et al Exome sequencing identifies recurrent BCOR alterations and the absence of KLF2, TNFAIP3 and MYD88 mutations in splenic diffuse red pulp small B-cell lymphoma. Haematologica. 2017;102(10):1758-1766

58. Maitre E, Bertrand P, Maingonnat C, et al. New generation sequencing of targeted genes in the classical and the variant form of hairy cell leukemia highlights mutations in epigenetic regulation genes. Oncotarget. 2018;9(48):28866-28876.

59. Staiger AM, Ott MM, Parmentier S, et al Allele-specific PCR is a powerful tool for the detection of the MYD88 L265P mutation in diffuse large B cell lymphoma and decalcified bone marrow samples. $\mathrm{Br} J$ Haematol. 2015;171(1):145-148.

60. Hamadeh F, MacNamara SP, Aguilera NS Swerdlow SH, Cook JR. MYD88 L265P mutation analysis helps define nodal lymphoplasmacytic lymphoma. Mod Pathol 2015;28(4):564-574.

61. King RL, Gonsalves WI, Ansell SM, et al. Lymphoplasmacytic lymphoma With a nonIgM paraprotein shows clinical and pathologic heterogeneity and may harbor MYD88 L265P mutations. Am J Clin Pathol 2016;145(6):843-851.

62. Varettoni M, Zibellini S, Boveri E, et al. A risk-stratification model based on the initial concentration of the serum monoclonal protein and MYD88 mutation status identifies a subset of patients with IgM monoclonal gammopathy of undetermined significance at high risk of progression to Waldenstrom macroglobulinaemia or other lymphoproliferative disorders. Br J Haematol. 2019 Jul 5. [Epub ahead of print]

63. Angelova EA, Li S, Wang W, et al. IgM plasma cell myeloma in the era of novel therapy: a clinicopathological study of 17 cases. Hum Pathol. 2019;84:321-334.

64. Li ZM, Rinaldi A, Cavalli A, et al. MYD88 somatic mutations in MALT lymphomas. B J Haematol. 2012;158(5):662-664.

65. Moody S, Escudero-Ibarz L, Wang M, et al Significant association between TNFAIP3 inactivation and biased immunoglobulin heavy chain variable region 4-34 usage in mucosa-associated lymphoid tissue lymphoma. J Pathol. 2017;243(1):3-8. 
Clinical relevance of MYD88 mutations in B-NHL

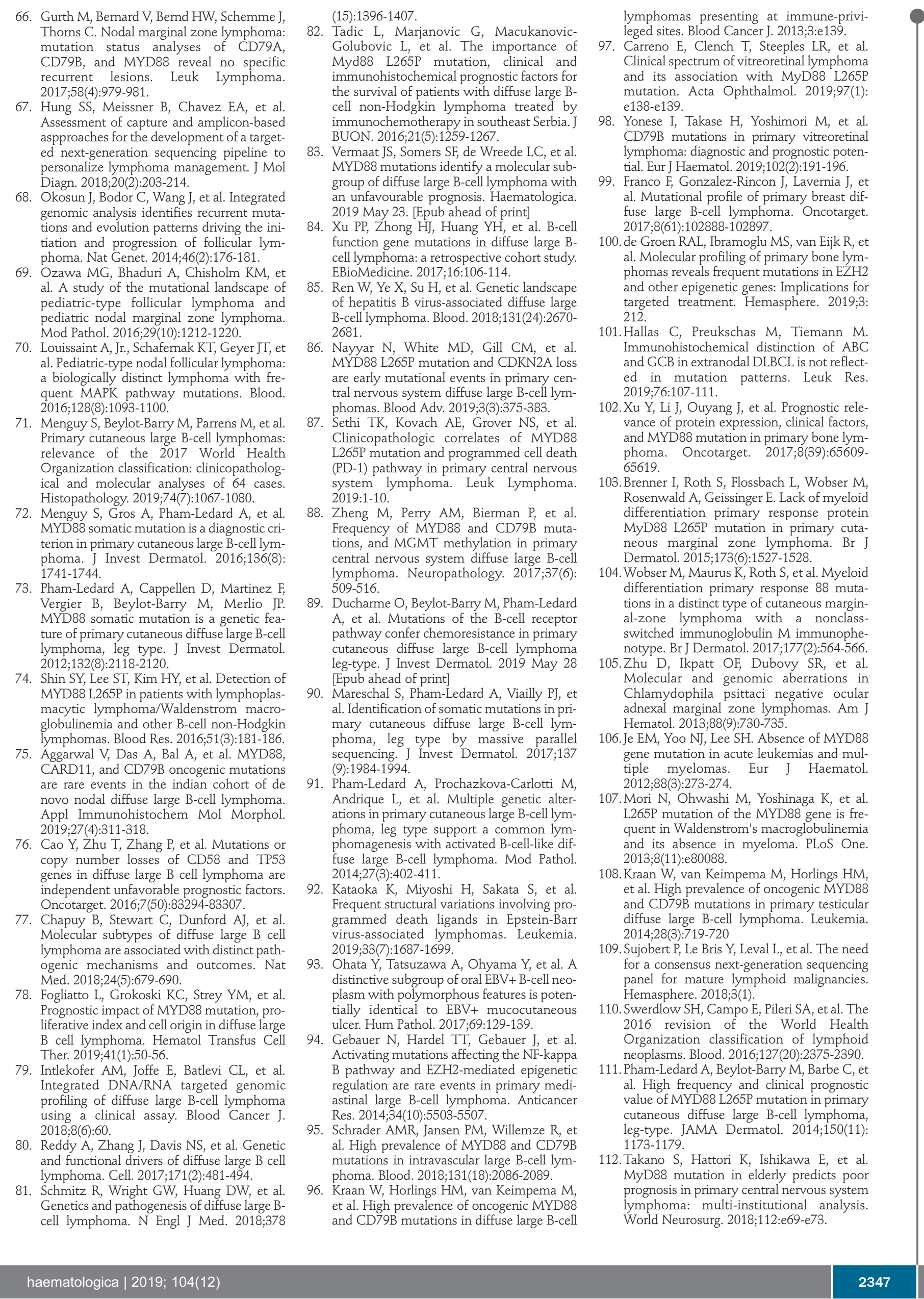


113. Yu S, Luo H, Pan M, et al. High frequency and prognostic value of MYD88 L265P mutation in diffuse large B-cell lymphoma with R-CHOP treatment. Oncol Lett. 2018;15(2):1707-1715.

114. Lee YS, Liu J, Fricano KA, et al. Lack of a Prognostic impact of the MyD88 L265P mutation for diffuse large B cell lymphoma patients undergoing autologous stem cell transplantation. Biol Blood Marrow Transplant. 2017;23(12): 2199-2204.

115. Parry M, Rose-Zerilli MJ, Ljungstrom V, et al. Genetics and prognostication in splenic marginal zone lymphoma: revelations from deep sequencing. Clin Cancer Res. 2015;21(18):4174-4183.

116. Gertz MA. Waldenstrom macroglobulinemia: 2019 update on diagnosis, risk stratification, and management. Am J Hematol. 2019;94(2):266-276.

117. Treon SP, Gustine J, Xu L, et al. MYD88 wildtype Waldenstrom macroglobulinaemia: differential diagnosis, risk of histological transformation, and overall survival. $\mathrm{Br} \mathrm{J}$ Haematol. 2018;180(3):374-380.

118. Hunter ZR, Xu L, Tsakmaklis N, et al. Insights into the genomic landscape of MYD88 wild-type Waldenstrom macroglobulinemia. Blood Adv. 2018;2(21): 2937-2946.

119. Weber ANR, Cardona Gloria Y Cinar O, Reinhardt HC, Pezzutto A, Wolz OO. Oncogenic MYD88 mutations in lymphoma: novel insights and therapeutic possibilities. Cancer Immunol Immunother. 2018;67(11):1797-1807.

120. Grommes C, Pastore A, Palaskas N, et al. Ibrutinib unmasks critical role of bruton tyrosine kinase in primary CNS pymphoma. Cancer Discov. 2017;7(9):1018-1029.

121. Younes A, Sehn LH, Johnson P, et al. Randomized phase III trial of ibrutinib and rituximab plus cyclophosphamide, doxorubicin, vincristine, and prednisone in non-germinal center B-cell diffuse large B-cell lymphoma. I Clin Oncol. 2019;37 (15):12851295.

122. Chen JG, Liu X, Munshi $M$, et al. BTK(Cys481Ser) drives ibrutinib resistance via ERK1/2 and protects BTK(wild-type)
MYD88-mutated cells by a paracrine mechanism. Blood. 2018;131(18):2047-2059.

123. Woyach JA, Furman RR, Liu TM, et al. Resistance mechanisms for the Bruton's tyrosine kinase inhibitor ibrutinib. N Engl J Med. 2014;370(24):2286-2294.

124. Cao Y, Hunter ZR, Liu X, et al. CXCR4 WHIM-like frameshift and nonsense mutations promote ibrutinib resistance but do not supplant MYD88(L265P) -directed survival signalling in Waldenstrom macroglobulinaemia cells. Br J Haematol. 2015;168(5) 701-707.

125. Byrd JC, Harrington B, O'Brien S, et al. Acalabrutinib (ACP-196) in relapsed chronic lymphocytic leukemia. N Engl J Med. 2016;374(4):323-332

126. Wang M, Rule S, Zinzani PL, et al Acalabrutinib in relapsed or refractory mantle cell lymphoma (ACE-LY-004): a singlearm, multicentre, phase 2 trial. Lancet. 2018;391(10121):659-667.

127. Trotman J, Opat S, Marlton P, et al. Bruton's tyrosine kinase (Btk) inhibitor Bgb-3111 demonstrates high very good partial response (VGPR) rate in patients with Waldenström macroglobulinemia (Wm). Hematol Oncol. 2017;35(S2):70-71.

128. Ghobrial IM, Witzig TE, Gertz M, et al Long-term results of the phase II trial of the oral mTOR inhibitor everolimus (RAD001) in relapsed or refractory Waldenstrom Macroglobulinemia. Am J Hematol. 2014;89 (3):237-242.

129. Forero-Torres A, Ramchandren R, Yacoub A, et al. Parsaclisib, a potent and highly selective PI3Kdelta inhibitor, in patients with relapsed or refractory B-cell malignancies. Blood. 2019;133(16):1742-1752.

130. He Y, Li J, Ding N, et al. Combination of enzastaurin and ibrutinib synergistically induces anti-tumor effects in diffuse large B cell lymphoma. J Exp Clin Cancer Res. 2019;38(1):86.

131.Liu X, Hunter ZR, Xu L, et al. Targeting myddosome assembly in Waldenstrom macroglobulinaemia. $\mathrm{Br} J$ Haematol. 2017;177(5):808-813.

132. Nelde A, Walz IS, Kowalewski DJ, et al. HLA class I-restricted MYD88 L265P- derived peptides as specific targets for lymphoma immunotherapy. Oncoimmunology. 2017;6(3):e1219825.

133. Nielsen JS, Chang AR, Wick DA, et al. Mapping the human $\mathrm{T}$ cell repertoire to recurrent driver mutations in MYD88 and EZH2 in lymphoma. Oncoimmunology. 2017;6(7):e1321184

134. Qiu H, Gong S, Xu L, et al. MYD88 L265P mutation promoted malignant $\mathrm{B}$ cell resistance against $\mathrm{T}$ cell-mediated cytotoxicity via upregulating the IL-10/STAT3 cascade. Int Immunopharmacol. 2018;64:394-400.

135. Camus V, Jardin F, Tilly H. The value of liquid biopsy in diagnosis and monitoring of diffuse large B-cell lymphoma: recent developments and future potential. Expert Rev Mol Diagn. 2017;17(6):557-566.

136. Scherer F, Kurtz DM, Newman AM, et al. Distinct biological subtypes and patterns of genome evolution in lymphoma revealed by circulating tumor DNA. Sci Transl Med. 2016;8(364):364ra155

137. Hattori K, Sakata-Yanagimoto M, Kusakabe $\mathrm{M}$, et al. Genetic evidence implies that primary and relapsed tumors arise from common precursor cells in primary central nervous system lymphoma. Cancer Sci. 2019;110(1):401-407.

138. Camus V, Sarafan-Vasseur N, Bohers E, et al Digital PCR for quantification of recurrent and potentially actionable somatic mutations in circulating free DNA from patients with diffuse large B-cell lymphoma. Leuk Lymphoma. 2016;57(9):2171-2179.

139. Bohers E, Viailly PJ, Becker S, et al. Noninvasive monitoring of diffuse large B-cell lymphoma by cell-free DNA high-throughput targeted sequencing: analysis of a prospective cohort. Blood Cancer J. 2018;8(8):74.

140. Kurtz DM, Scherer F, Jin MC, et al Circulating tumor DNA measurements as early outcome predictors in diffuse large Bcell lymphoma. J Clin Oncol. 2018;36(28): 2845-2853.

141.Witzig TE, Reeder CB, LaPlant BR, et al. A phase II trial of the oral mTOR inhibitor everolimus in relapsed aggressive lymphoma. Leukemia. 2011;25(2):341-347. 